\title{
Clinical features and predictive factors of coagulation syndrome after endoscopic submucosal dissection for early gastric neoplasm
}

\author{
Hyuk Lee $\cdot$ Kyung Seok Cheoi $\cdot$ Hyunsoo Chung $\cdot$ \\ Jun Chul Park · Sung Kwan Shin • Sang Kil Lee • \\ Yong Chan Lee
}

Received: 21 March 2011/Accepted: 4 June 2011/Published online: 15 July 2011

(C) The International Gastric Cancer Association and The Japanese Gastric Cancer Association 2011

\begin{abstract}
Background Various endoscopic submucosal dissection (ESD)-related complications, such as perforation or bleeding, occur frequently. However, the clinical course of coagulation syndrome (CS) after ESD is not known. The aim of this study was to clarify the clinical outcomes and predictive factors of CS after ESD for early gastric lesions.

Methods ESD procedures were performed in the typical sequence (marking, incision, and submucosal dissection). Four hundred and ninety-five patients with early gastric neoplasms were classified into two groups based on their clinical course after ESD: one group with post-ESD CS and the other with a normal clinical course. The clinical outcomes of the CS group were analyzed, and various clinical and pathological factors related to post-ESD CS were investigated using univariate and multivariate analyses.

Results Coagulation syndrome occurred after ESD in 35 patients. In the CS group, the median period of inflammatory symptoms was $23.7 \pm 12.0 \mathrm{~h}$, and no blood cultures showed bacteremia. Multivariate analysis demonstrated that a tumor size of more than $1.5 \mathrm{~cm}$ [odds ratio (OR) 5.99 , $P<0.001]$, tumor location in the middle third of the stomach (OR 2.84, $P=0.005$ ), and a procedural time longer than $45 \mathrm{~min}(\mathrm{OR} 2.71, P=0.033$ ) were independent risk factors for this complication. All patients with CS presented with a favorable outcome, irrespective of antibiotic treatment.
\end{abstract}

H. Lee $\cdot$ K. S. Cheoi $\cdot$ H. Chung - J. C. Park ·

S. K. Shin · S. K. Lee · Y. C. Lee $(\bowtie)$

Division of Gastroenterology, Department of Internal Medicine,

Institute of Gastroenterology,

Yonsei University College of Medicine,

134 Shinchon-dong, Sodaemun-gu, Seoul 120-752, Korea

e-mail: leeyc@yuhs.ac
Conclusions This study suggests that CS occurs with an incidence of $7.1 \%$ after ESD for gastric lesions, and the factors associated with post-ESD CS include tumor size and location, and procedural duration.

Keywords Endoscopic submucosal dissection .

Coagulation syndrome $\cdot$ Complication · Gastric neoplasm

\section{Introduction}

Endoscopic mucosal resection (EMR) of early gastric cancers has become a widely accepted, standard procedure. Various EMR techniques have been developed, including suction or lift techniques such as EMR ligation, EMR cap, and EMR strip biopsy. The main problem with these conventional EMR methods is the retrieval of multiple specimens after the resection of large lesions, because en-bloc resection is considered ideal for the accurate histopathological evaluation of the tumors. This limitation of EMR has been overcome by the development of endoscopic submucosal dissection (ESD). ESD is now performed more commonly than any other technique for the treatment of early gastric neoplasms, because it preserves the stomach, with en-bloc resection, and provides tumor-free margins [1-5]. Despite this advantage, ESD is considered to require a special technique and to entail a high rate of complications, particularly perforation and postoperative bleeding $[6,7]$. A considerable number of studies of the major complications associated with ESD have been conducted [8-10]. Besides these major adverse events, minor problems are also encountered frequently after ESD. However, these tend to be underestimated. Temporary inflammatory signs, in particular, often occur during the post-ESD period, including fever, abnormal levels of inflammatory 
markers, and upper abdominal pain, with or without symptoms of peritoneal irritation [11].

Although coagulation syndrome has been reported after colon polypectomy, no attempt has been made to evaluate post-ESD coagulation syndrome. The incidence of postpolypectomy coagulation syndrome caused by transmural burns is $0.5-1.2 \%$ [12-14]; it is presumed that the incidence of ESD-related coagulation syndrome is higher, because more frequent and repetitive electrocoagulation is performed during this procedure. However, this has not yet been established.

A computed tomography (CT) study of transmural air leaks after ESD suggested that these were associated with post-ESD inflammatory symptoms [11]. In another case report of post-ESD ischemia, this adverse event led to inflammatory symptoms. It was assumed that this gastric ischemia was related to a compromised microcirculation, attributed to the underlying disease or a large-volume submucosal injection during the procedure [15].

The aim of our study was to examine the clinical features and outcomes in patients with post-ESD coagulation syndrome. We also hoped to clarify the predictive factors influencing the occurrence of this complication.

\section{Methods}

\section{Patients}

The standard or extended criteria for ESD included: (a) histopathological diagnosis by biopsy of a well- or moderately differentiated adenocarcinoma or dysplasia (adenoma); (b) tumor invasion of the mucosa or minute submucosal layers defined by endoscopic ultrasonography or endoscopic presentation; (c) tumor size of $\leq 3 \mathrm{~cm}$, if minute submucosal invasion or a tumor with ulceration was suspected; and (d) a tumor of any size if it was a differentiated adenocarcinoma without ulceration or submucosal invasion. Fourteen gastric lesions with characteristics beyond the extended criteria were included in this investigation. The exclusion criteria included: (a) macroperforation or microperforation; (b) infectious or inflammatory disease, such as pneumonia, upper respiratory infection, or urinary tract infection; (c) antibiotic treatment before the endoscopic procedure; and (d) cases of multiple tumors. Macroperforation was defined as a gross defect noted during the procedure, with extraluminal organs, fatty tissues, or space visible through the lesion, and microperforation was defined as a perforation identified as a pneumoperitoneum, seen on plain radiographs after the ESD. Patients with pyrexia (temperature of $>38.3^{\circ} \mathrm{C}$ ) and upper abdominal pain or tenderness after ESD, with or without symptoms of peritoneal irritation, were regarded as showing symptoms of post-ESD coagulation syndrome.

\section{ESD technique}

For sedation, midazolam $(0.05-0.1 \mathrm{mg} / \mathrm{kg})$ or propofol ( $2 \mathrm{mg} / \mathrm{kg}$ per h) was used, and cardiorespiratory function was monitored during the procedure. The typical ESD procedural sequence consisted of marking, incision, and submucosal dissection, with simultaneous hemostasis. After the target lesion was identified, marking dots were made circumferentially at about $5 \mathrm{~mm}$ lateral to the margin of the lesion, using a needle knife (KD-1L-1; Olympus Optical, Tokyo, Japan) or a needle knife papillotome (MTW Endoscopy, Wesel, Germany). After marking, submucosal injections of various solutions, including normal saline solution and an epinephrine mixture or hyaluronic acid mixture, were made around the lesion to lift it off the muscle layer. An initial incision of the mucosa was then made with a needle knife to allow the insertion of the tip of the knife into the submucosa. After the initial incision, a circumferential mucosal incision was made outside the marking dots to separate the lesion from the surrounding nonneoplastic mucosa. This incision was performed with an electrosurgical knife, such as a needle knife, Flex (KD-630L; Olympus), or an insulated tipped knife (KD-610L; Olympus), with a high-frequency generator (Erbotom ICC 200; ERBE Elektromedizin, Tubingen, Germany). After the circumferential incision was made, an additional submucosal injection of the same solutions as those used around the lesion was given beneath the lesion. Finally, the submucosal layer was directly dissected with one of the specified knives until complete removal was achieved. An electrocautery snare (SD-9U-1 or SD-12U-1; Olympus) was used in the final step of the ESD when appropriate. During the ESD, we performed endoscopic hemostasis, with either the knife itself or hemostatic forceps (FD-410LR; Olympus) whenever active bleeding was noticed. After the ESD, we treated any oozing or exposed vessel with preventive endoscopic hemostasis. The setting of the high-frequency generator (Elektromedizin, Tubingen, Germany) was pulsed argon plasma coagulation (APC) of $20 \mathrm{~W}$ or forced coagulation of $20 \mathrm{~W}$ for marking, Endocut Q or Dry cut of $80 \mathrm{~W}$ for incision and dissection, and forced coagulation of $60 \mathrm{~W}$ for hemostasis. During the procedure, the degree of bleeding was evaluated and described by the operator.

\section{Post-ESD management}

Immediately after the completion of the ESD, all patients underwent chest and abdominal X-rays. Patients without complications started drinking water on the day after the ESD and our principle was to discharge the patients within 
4-7 days if they had no post-ESD complications. The patients were prescribed proton pump inhibitors to heal any ESD-related artificial ulcers.

Data and statistical analysis

Detailed information on the endoscopic images, comorbidities, drug treatments, pathological examinations, and other potential risk factors was obtained retrospectively from the patients' medical records, together with patient interviews conducted during the initial medical examination. Post-ESD coagulation syndrome was analyzed in relation to the clinicopathological features and procedurerelated factors. In the statistical analyses we compared patients with post-ESD coagulation syndrome with patients who had a normal clinical course. Descriptive data are presented as numbers of patients (\%) or as means \pm standard deviations (SD). Continuous data were compared

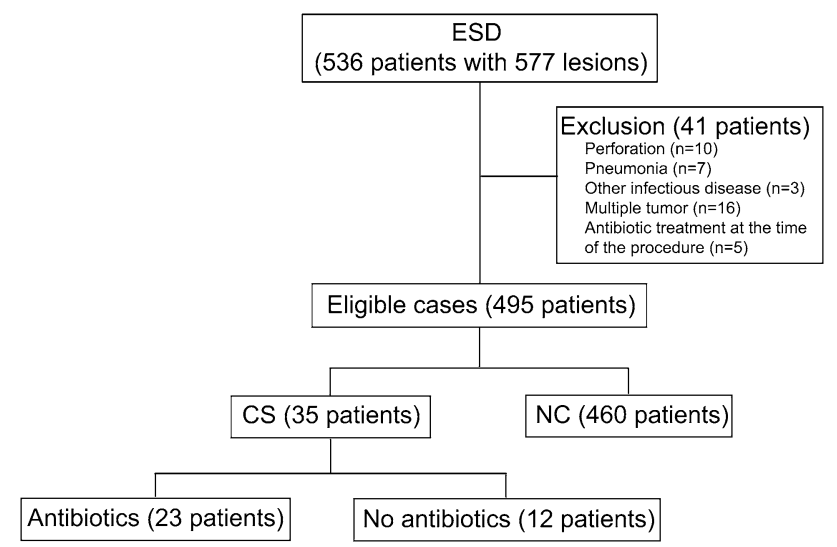

Fig. 1 Patient selection and clinical course after endoscopic submucosal dissection $(E S D)$. $C S$ coagulation syndrome, $N C$ normal clinical course using the independent $t$-test, and categorical variables were tested by the corrected $\chi^{2}$ method. Univariate and multivariate logistic regression analyses were used to assess potentially predictive factors for coagulation syndrome after ESD. These analyses were conducted by categorizing the factors as dichotomous variables (below or above the median value). The criterion for statistical significance was $P<0.05$. The analyses were performed using SPSS (version 18.0; SPSS, Chicago, IL, USA).

\section{Results}

Clinical features of post-ESD coagulation syndrome

In total, 536 patients with 577 histopathologically confirmed early gastric cancers (EGCs) or adenomas underwent ESD at Severance Hospital, Yonsei University College of Medicine, Seoul, Korea. Among them, 41 patients were excluded from the analysis because of evidence of perforation $(n=10)$, aspiration pneumonia $(n=7)$, infectious diseases $(n=3)$, cases of multiple tumors $(n=16)$, or antibiotic treatment at the time of the procedure $(n=5)$. Thus, 495 patients were included in our analysis (Fig. 1). Thirty-five patients $(7.1 \%)$ were diagnosed with post-ESD coagulation syndrome. The patients were classified into two groups: the group with post-ESD coagulation syndrome (CS group, $n=35$ ) and the group with a normal clinical course (NC group, $n=460$ ). The clinical characteristics of the patients are given in Table 1. The mean age of the patients was 61.9 years (range 37-84 years) in the CS group and 59.2 years (range 34-82 years) in the NC group. The distribution of men and women did not differ between the two groups. In the CS group, the median duration of pyrexia was $23.7 \mathrm{~h}$ (range

Table 1 Clinical characteristics of patients, lesions, and procedures

\begin{tabular}{|c|c|c|c|c|}
\hline & Total $(n=495)$ & $\mathrm{CS}(n=35)$ & $\mathrm{NC}(n=460)$ & $P$ value \\
\hline Age $(\text { years })^{\mathrm{a}}$ & $60.3( \pm 11.1)$ & $61.9( \pm 14.9)$ & $59.2( \pm 10.5)$ & 0.791 \\
\hline Gender (M:F) & $1.4: 1$ & $1.7: 1$ & $1.4: 1$ & 0.291 \\
\hline Tumor size $(\mathrm{cm})^{\mathrm{a}}$ & $1.4( \pm 0.7)$ & $2.4( \pm 1.2)$ & $1.2( \pm 0.5)$ & 0.020 \\
\hline Final pathology LGD/HGD/EGC (\%) & $51.1 / 19.6 / 29.3$ & $48.6 / 17.1 / 34.3$ & $51.3 / 19.8 / 28.9$ & 0.571 \\
\hline Procedure time $(\min )^{\mathrm{a}}$ & $44.8( \pm 18.7)$ & $60.3( \pm 26.4)$ & $40.6( \pm 11.9)$ & 0.016 \\
\hline Post-ESD coagulation time (min) & $3.7 \pm 3.7$ & $4.2 \pm 3.6$ & $3.5 \pm 4.1$ & 0.211 \\
\hline Duration of pyrexia $(h)^{a}$ & & $23.7( \pm 12.0)$ & & \\
\hline White blood cell count $(/ \mu \mathrm{l})$ & $9,232( \pm 1,652)$ & $11,335( \pm 2,173)$ & $8,788( \pm 1,353)$ & 0.021 \\
\hline C-reactive protein $(\mathrm{mg} / \mathrm{L})$ & $8.8( \pm 7.1)$ & $14.2( \pm 13.1)$ & $6.5( \pm 7.2)$ & 0.025 \\
\hline Duration of hospital stay (days) ${ }^{\mathrm{a}}$ & $5.1( \pm 2.6)$ & $7.3( \pm 3.8)$ & $4.4( \pm 1.9)$ & 0.019 \\
\hline
\end{tabular}

$C S$ coagulation syndrome, $N C$ normal clinical course $L G D$ low-grade dysplasia, $H G D$ high-grade dysplasia, $E G C$ early gastric cancer, $E S D$ endoscopic submucosal dissection

a The results are presented as medians $\pm \mathrm{SD}$ 
Table 2 Univariate analysis of coagulation syndrome according to patient-related variables

\begin{tabular}{llll}
\hline Risk factor $(n, \%)$ & $\begin{array}{l}\text { CS } \\
(n=35)\end{array}$ & $\begin{array}{l}\text { NC } \\
(n=460)\end{array}$ & $P$ value \\
\hline $\begin{array}{l}\text { Age (years) } \\
\geq 60\end{array}$ & $14(40.0)$ & $180(39.1)$ & 0.601 \\
$<60$ & $21(60.0)$ & $280(60.9)$ & \\
Gender & $22(62.9)$ & $268(58.3)$ & 0.412 \\
Male & $13(37.1)$ & $192(41.7)$ & \\
Female & & & \\
Comorbidity & $3(8.6)$ & $36(7.8)$ & 0.790 \\
Diabetes & $5(14.3)$ & $61(13.3)$ & 0.823 \\
Hypertension & $1(2.9)$ & $9(2.0)$ & 0.551 \\
Chronic liver disease & & & \\
Medication & $4(11.4)$ & $47(10.2)$ & 0.658 \\
NSAIDs & $5(14.3)$ & $75(16.3)$ & 0.703 \\
Aspirin or antiplatelet agents & $1(2.9)$ & $8(1.7)$ & 0.559 \\
Warfarin & & & \\
\hline
\end{tabular}

NSAID nonsteroidal anti-inflammatory agent

6-46 h). Blood cultures were performed in all patients, and no case of bacteremia was observed. The procedural time was significantly longer in the CS group than in the NC group $(60.3 \pm 26.4$ vs. $40.6 \pm 11.9 \mathrm{~min}$, respectively; $P=0.016$ ), as was the duration of the hospital stay (7.3 \pm 3.8 vs. $4.4 \pm 1.9$ days, respectively; $P=0.019$ ). The CS group also had larger tumors than the NC group $(2.4 \pm 1.2$ vs. $1.2 \pm 0.5 \mathrm{~cm}$, respectively; $P=0.020)$. Levels of inflammatory markers such as white blood cell count and C-reactive protein were significantly higher in the CS group than in the NC group. All patients with coagulation syndrome experienced clinical resolution without surgical treatment.

Predictive factors of coagulation syndrome

As shown in Tables 2 and 3, a univariate analysis revealed that the factors associated with the occurrence of coagulation syndrome after ESD included tumor size, tumor location in the middle third of the stomach, the volume of the solution injected submucosally, duration of the procedure, and major bleeding. There was no significant difference between the groups in factors such as patient age, drug history (such as aspirin, nonsteroidal anti-inflammatory drugs, or coumadin), type of submucosal injection solution, main type of knife used, final histology, or clinical outcome (in terms of en-bloc resection and complete resection rates). Tumors greater than $1.5 \mathrm{~cm}$ were more frequent in the CS group than in the NC group (48.6 vs. $14.1 \%$, respectively; $P<0.001$ ), as were those located in the middle third of the stomach ( 40.0 vs. $20.6 \%$, respectively; $P=0.008$ ); also more frequent in the CS group
Table 3 Univariate analysis of coagulation syndrome according to procedure-related variables

\begin{tabular}{|c|c|c|c|}
\hline Risk factor $(n, \%)$ & $\begin{array}{l}\mathrm{CS} \\
(n=35)\end{array}$ & $\begin{array}{l}\mathrm{NC} \\
(n=460)\end{array}$ & $P$ value \\
\hline \multicolumn{4}{|l|}{ Final pathology } \\
\hline Adenocarcinoma & $12(34.3)$ & $133(28.9)$ & \multirow[t]{2}{*}{0.611} \\
\hline Adenoma & $23(65.7)$ & $327(71.1)$ & \\
\hline \multicolumn{4}{|l|}{ Tumor size $(\mathrm{cm})$} \\
\hline$\geq 1.5$ & 17 (48.6) & $65(14.1)$ & \multirow[t]{2}{*}{$<0.001$} \\
\hline$<1.5$ & $18(51.4)$ & $395(85.9)$ & \\
\hline \multicolumn{4}{|l|}{ Tumor location } \\
\hline Upper third & $8(22.9)$ & $79(17.2)$ & \multirow[t]{3}{*}{0.008} \\
\hline Middle third & $14(40.0)$ & $95(20.6)$ & \\
\hline Lower third & $13(37.1)$ & $286(62.2)$ & \\
\hline \multicolumn{4}{|l|}{ Kind of injection solution } \\
\hline Normal saline with epinephrine & $13(37.1)$ & $190(41.3)$ & \multirow[t]{2}{*}{0.623} \\
\hline Hyaluronic acid & $22(62.9)$ & $270(58.7)$ & \\
\hline \multicolumn{4}{|l|}{ Volume of injection solution (mL) } \\
\hline$\geq 45$ & $24(68.6)$ & $217(47.2)$ & \multirow[t]{2}{*}{0.042} \\
\hline$<45$ & $11(31.4)$ & $243(52.8)$ & \\
\hline \multicolumn{4}{|l|}{ Main type of knife } \\
\hline Insulated-tip knife & $30(85.7)$ & $376(81.8)$ & \multirow[t]{4}{*}{0.709} \\
\hline Flex knife & $4(11.4)$ & $54(11.7)$ & \\
\hline Needle knife & $1(2.9)$ & $22(4.8)$ & \\
\hline Other knives & 0 & $8(1.7)$ & \\
\hline \multicolumn{4}{|l|}{ Total procedural time (min) } \\
\hline$\geq 45$ & $27(77.1)$ & $221(48.0)$ & \multirow[t]{2}{*}{0.001} \\
\hline$<45$ & $8(22.9)$ & $239(52.0)$ & \\
\hline \multicolumn{4}{|l|}{ Post-ESD coagulation time (min) } \\
\hline$\geq 3$ & $20(57.1)$ & $241(52.4)$ & \multirow[t]{2}{*}{0.355} \\
\hline$<3$ & $15(42.9)$ & $219(47.6)$ & \\
\hline \multicolumn{4}{|l|}{ Bleeding during ESD } \\
\hline Major & $7(20.0)$ & $60(13.0)$ & \multirow[t]{3}{*}{0.038} \\
\hline Moderate & $15(42.9)$ & $197(42.8)$ & \\
\hline Minimal & $13(37.1)$ & $203(44.1)$ & \\
\hline \multicolumn{4}{|l|}{ Clinical outcome } \\
\hline En-bloc resection rate & $34(97.1)$ & $439(95.4)$ & 0.782 \\
\hline Complete resection rate & $32(91.4)$ & $428(93.0)$ & 0.562 \\
\hline
\end{tabular}

than in the $\mathrm{NC}$ group were a submucosal injection solution volume of more than $45 \mathrm{~mL}$ (68.6 vs. $47.2 \%$, respectively; $P=0.042)$, a procedural time of more than $45 \mathrm{~min}(77.1$ vs. $48.0 \%$, respectively; $P=0.001$ ), and the occurrence of major bleeding during ESD (20.0 vs. $13.0 \%$, respectively; $P=0.038$ ). A multivariate analysis that included the variables described above showed that tumor size (odds ratio $[\mathrm{OR}]=5.99, P<0.001)$, tumor location $(\mathrm{OR}=$ $2.84, P=0.005)$, and procedural duration $(\mathrm{OR}=2.71$, $P=0.033)$ independently affected the occurrence of coagulation syndrome (Table 4). 
Table 4 Logistic regression model for the predictors of coagulation syndrome after endoscopic submucosal dissection

\begin{tabular}{|c|c|c|c|}
\hline Risk factor & Odds ratio & $95 \% \mathrm{CI}$ & $P$ value \\
\hline \multicolumn{4}{|c|}{ Tumor size $(\mathrm{cm})$} \\
\hline$\geq 1.5$ & 5.99 & $2.89-12.42$ & $<0.001$ \\
\hline$<1.5^{\mathrm{a}}$ & 1 & & \\
\hline \multicolumn{4}{|l|}{ Tumor location } \\
\hline Upper third & 1.69 & $0.61-4.69$ & 0.318 \\
\hline Middle third & 2.84 & $1.39-6.76$ & 0.005 \\
\hline Lower third ${ }^{\mathrm{a}}$ & 1 & & \\
\hline \multicolumn{4}{|c|}{ Volume of injection solution $(\mathrm{mL})$} \\
\hline$\geq 45$ & 1.26 & $0.56-2.89$ & 0.581 \\
\hline$<45^{\mathrm{a}}$ & 1 & & \\
\hline \multicolumn{4}{|c|}{ Procedural time (min) } \\
\hline$\geq 45$ & 2.71 & $1.08-6.81$ & 0.033 \\
\hline$<45^{\mathrm{a}}$ & 1 & & \\
\hline \multicolumn{4}{|c|}{ Bleeding during ESD } \\
\hline Major & 1.71 & $0.59-4.98$ & 0.331 \\
\hline Moderate & 0.84 & $0.32-2.20$ & 0.731 \\
\hline Minimal $^{\mathrm{a}}$ & 1 & & \\
\hline
\end{tabular}

CI confidence interval

${ }^{\text {a }}$ Reference group

Table 5 Comparison of clinical characteristics according to antibiotic treatment

\begin{tabular}{llll}
\hline & $\begin{array}{l}\text { With antibiotics } \\
(n=23)\end{array}$ & $\begin{array}{l}\text { Without } \\
\text { antibiotics } \\
(n=12)\end{array}$ & $P$ value \\
\hline Age (years) & $62.1( \pm 15.5)$ & $60.1( \pm 13.8)$ & 0.767 \\
Gender (M:F) & $1.6: 1$ & $2.0: 1$ & 0.621 \\
Comorbidity & $7(30.4 \%)$ & $2(16.7 \%)$ & 0.202 \\
$\begin{array}{l}\text { Tumor size (cm) } \\
\begin{array}{l}\text { Procedural time } \\
\text { (min) }\end{array}\end{array}$ & $2.3( \pm 1.3)$ & $2.5( \pm 0.9)$ & 0.615 \\
$\begin{array}{l}\text { Leukocytosis } \\
\begin{array}{c}\text { Blood culture-based } \\
\text { bacteremia }\end{array}\end{array}$ & $06.7( \pm 23.6)$ & $61.8( \pm 31.1)$ & 0.558 \\
$\begin{array}{l}\text { Duration of pyrexia } \\
\text { (h) }\end{array}$ & $24.3( \pm 17.7)$ & $22.5( \pm 12.2)$ & 0.791 \\
$\begin{array}{l}\text { Duration of hospital } \\
\text { stay (days) }\end{array}$ & $7.5( \pm 3.9)$ & $7.2( \pm 2.9)$ & 0.669 \\
\hline
\end{tabular}

Effects of antibiotic treatment

Twenty-three patients in the CS group (65.7\%) were treated with antibiotics. When the groups with and without antibiotic treatment were compared, there was no difference in their clinicopathological features (Table 5). CT scans were performed after the procedure in three of the patients treated with antibiotics (Fig. 2). No remarkable findings were noted on these examinations, except for regional wall thickening of the stomach. Importantly, the duration of pyrexia and the length of the hospital stay did not differ significantly between the two groups.

\section{Discussion}

The principal findings of this study are that coagulation syndrome occurred at a rate of almost once in every 14 ESDs and that no serious clinical events occurred with this complication.

ESD is a widely used procedure that preserves the stomach and allows one-piece resection with tumor-free margins, even in cases of large and ulcerative lesions. However, ESD is a technically difficult procedure and is generally thought to have a much higher rate of complications, such as bleeding and perforation, than does conventional endoscopic resection [1-7]. The rate of bleeding related to ESD is reported to be $7-15.6 \%$ and the rate of perforation is $1.2-4 \%[8-10,16]$. Consequently, large tumors or tumors with ulceration, which are technically difficult to resect, should only be treated with ESD when the procedure can be performed at endoscopic facilities where the endoscopists have a high level of expertise and experience $[5,17]$. Other than major complications, various minor problems are frequently associated with this procedure. However, these complications tend to be underestimated because of self-limiting course, regardless of their frequency. Clinical effects, such as abdominal pain, nausea, vomiting, or fever, are relatively common in the post-ESD period. Many patients experience inflammatory or infectious symptoms and signs after resection, such as abdominal pain accompanied by pyrexia of unknown origin, with leukocytosis (albeit transient) [11]. Coagulation syndrome is well known in the field of colonpolypectomy-induced complications, and is associated with thermal transmural tissue injury incurred during electrocauterization. Tissue necrosis extends into the submucosa, causing symptomatic reactions of varying degrees. Some reports have estimated the incidence of coagulation syndrome to be $0.5-1.2 \%$ in patients who have undergone polypectomy. The treatments for this complication include discontinuation of oral intake, parenteral nutrition, and antibiotic treatment if needed, but not surgical treatment $[12,13,18-20]$.

Studies have mainly focused on the major complications associated with ESD. Perforation has become an especial object of attention because it is associated with a greater risk of significant morbidity and mortality, and requires emergency treatment $[9,21,22]$. The features of the lesions, such as their size, site, and fibrosis, are known to be significant risk factors for perforation [5, 23, 24]. Acute 

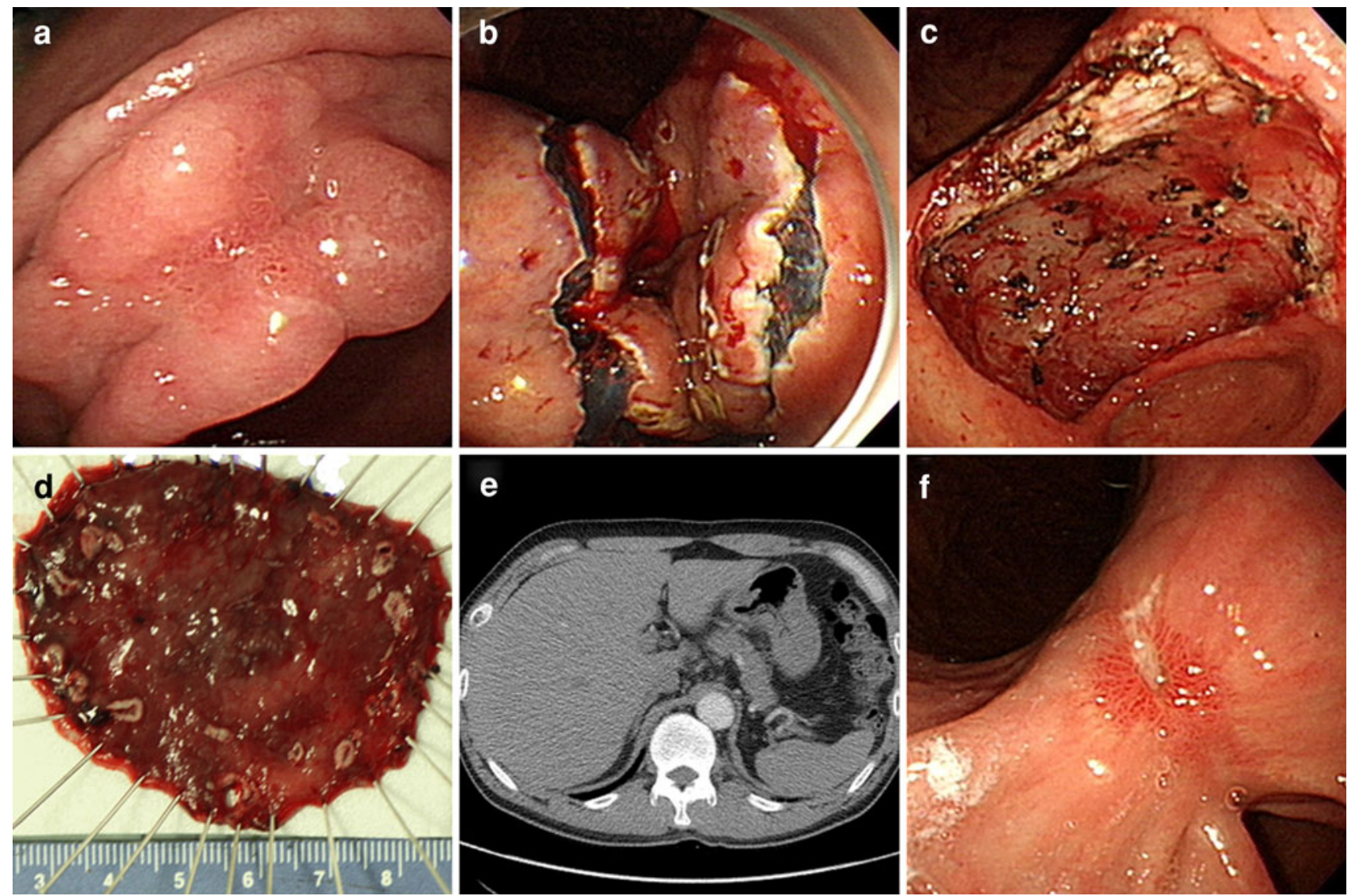

Fig. 2 Coagulation syndrome after procedure of endoscopic submucosal dissection (ESD) for early gastric cancer. a A type IIa + IIc early gastric cancer $(3.4 \times 2.5 \mathrm{~cm}$ in size $)$ was located on the lesser curvature side of the antrum. b After a submucosal injection of saline with epinephrine mixed with indigocarmine, a circumferential mucosal incision was made outside the marking dots to separate the lesion from the surrounding nonneoplastic mucosa. c After an additional submucosal injection, the submucosal connective tissue just beneath the lesion was directly dissected using an electrosurgical knife. The lesion was completely resected and the consequent artificial ulcer was seen. d The resected specimen with a central early gastric cancer. e Computed tomography (CT) scan showed mild wall thickening of the antrum without evidence of free air. $f$ On 3-month follow-up endoscopy, an $\mathrm{H} 2$ stage (small and regenerating epithelium-covering ulcer) artificial ulcer was noted

tumors and extended procedures seem to entail an increased frequency of electrocoagulation of bleeding vessels with hot biopsy forceps [17]. The reason for the frequent occurrence of this complication in the middle third of the stomach is unclear. It is presumed that the chance of transmural burns is high because the gastric wall in this location is comparatively thin and the gastric body is more hypervascular than the antrum. Major bleeding was not an independent factor associated with this complication. This seems to be attributable to the frequent use of mechanical hemostasis (including hemoclipping), together with electrocoagulation, in cases of massive bleeding, such as arterial pumping. In a report of postpolypectomy coagulation syndrome, the rate of complications differed according to the type of solution injected as the submucosal cushion [26]. On the contrary, our study showed that the volume and type of submucosal injection solution were not significantly associated with post-ESD coagulation 
syndrome. This may be because frequent, repetitive submucosal injections are performed in ESD, unlike polypectomy. Therefore, no unexpected loss of submucosal fluid tends to occur, regardless of the type of injection solution used in the ESD procedure.

It is unclear whether antibiotic treatment should be given for coagulation syndrome after ESD for gastric lesions. Antibiotic treatment has been recommended for postpolypectomy coagulation syndrome [14]. However, it does not seem to be reasonable that this therapeutic principle should be equally applicable to gastric ESD, because the risk of delayed perforation is lower and the preprocedural intraluminal condition is cleaner during gastric resection than during colon polypectomy. Although the present study was a retrospective analysis, we found that the efficacy of antibiotic treatment seemed to be insignificant, insofar as the clinicopathological features did not differ across the groups classified according to antibiotic treatment (Table 5). The negative findings for the blood cultures of all the patients with coagulation syndrome support this suggestion. However, this assumption should be verified with a systematic and randomized investigation.

The limitations of our study include a lack of CT-scan data for all patients with coagulation syndrome. It might also have been helpful to correlate the clinical diagnosis, such as coagulation syndrome, with the pathological diagnosis, such as transmural air leak.

This is a first review of coagulation syndrome after ESD for gastric lesions. This complication was relatively common, with an incidence of $7.1 \%$, but had a favorable outcome, irrespective of antibiotic treatment. Factors that were related independently to the occurrence of post-ESD coagulation syndrome included tumor size and location, and the duration of the procedure.

\section{References}

1. Soetikno RM, Gotoda T, Nakanishi Y, Soehendra N. Endoscopic mucosal resection. Gastrointest Endosc. 2003;57:567-79.

2. Ono H, Kondo H, Gotoda T, Shirao K, Yamaguchi H, Saito D, et al. Endoscopic mucosal resection for treatment of early gastric cancer. Gut. 2001;48:225-9.

3. Watanabe K, Ogata S, Kawazoe S, Koyama T, Kajiwara T, Shimoda Y, et al. Clinical outcomes of EMR for gastric tumors: historical pilot evaluation between endoscopic submucosal dissection and conventional mucosal resection. Gastrointest Endosc. 2006;63:776-82.

4. Muto M, Miyamoto S, Hosokawa A, Doi T, Ohtsu A, Yoshida S, et al. Endoscopic mucosal resection in the stomach using the insulated-tip needle-knife. Endoscopy. 2005;37:178-82.

5. Imagawa A, Okada H, Kawahara Y, Takenaka R, Kato J, Kawamoto H, et al. Endoscopic submucosal dissection for early gastric cancer: results and degrees of technical difficulty as well as success. Endoscopy. 2006;38:987-90.
6. Oka S, Tanaka S, Kaneko I, Mouri R, Hirata M, Kawamura T, et al. Advantage of endoscopic submucosal dissection compared with EMR for early gastric cancer. Gastrointest Endosc. 2006;64: 877-83.

7. Miyamoto S, Muto M, Hamamoto Y, Boku N, Ohtsu A, Baba S, et al. A new technique for endoscopic mucosal resection with an insulated-tip electrosurgical knife improves the completeness of resection of intramucosal gastric neoplasms. Gastrointest Endosc. 2002;55:576-81.

8. Jeon SW, Jung MK, Cho CM, Tak WY, Kweon YO, Kim SK, et al. Predictors of immediate bleeding during endoscopic submucosal dissection in gastric lesions. Surg Endosc. 2009;23: 1974-9.

9. Jeon SW, Jung MK, Kim SK, Cho KB, Park KS, Park CK, et al. Clinical outcomes for perforations during endoscopic submucosal dissection in patients with gastric lesions. Surg Endosc. 2010;24: 911-6.

10. Okada K, Yamamoto Y, Kasuga A, Omae M, Kubota M, Hirasawa $\mathrm{T}$, et al. Risk factors for delayed bleeding after endoscopic submucosal dissection for gastric neoplasm. Surg Endosc. 2011;25:98-107.

11. Onogi F, Araki H, Ibuka T, Manabe Y, Yamazaki K, Nishiwaki $\mathrm{S}$, et al. "Transmural air leak": a computed tomographic finding following endoscopic submucosal dissection of gastric tumors. Endoscopy. 2010;42:441-7.

12. Waye JD, Lewis BS, Yessayan S. Colonoscopy: a prospective report of complications. J Clin Gastroenterol. 1992;15:347-51.

13. Waye JD, Kahn O, Auerbach ME. Complications of colonoscopy and flexible sigmoidoscopy. Gastrointest Endosc Clin N Am. 1996;6:343-77.

14. Christie JP, Marrazzo J 3rd. "Mini-perforation" of the colonnot all postpolypectomy perforations require laparotomy. Dis Colon Rectum. 1991;34:132-5.

15. Probst A, Maerk1 B, Bittinger M, Messmann H. Gastric ischemia following endoscopic submucosal dissection of early gastric cancer. Gastric Cancer. 2010;13:58-61.

16. Chung IK, Lee JH, Lee SH, Kim SJ, Cho JY, Cho WY, et al. Therapeutic outcomes in 1000 cases of endoscopic submucosal dissection for early gastric neoplasms: Korean ESD Study Group multicenter study. Gastrointest Endosc. 2009;69:1228-35.

17. Mannen K, Tsunada S, Hara M, Yamaguchi K, Sakata Y, Fujise $\mathrm{T}$, et al. Risk factors for complications of endoscopic submucosal dissection in gastric tumors: analysis of 478 lesions. J Gastroenterol. 2010;45:30-6.

18. Parra-Blanco A, Kaminaga N, Kojima T, Endo Y, Tajiri A, Fujita R. Colonoscopic polypectomy with cutting current: is it safe? Gastrointest Endosc. 2000;51:676-81.

19. Nivatvongs S. Complications in colonoscopic polypectomy: lessons to learn from an experience with 1576 polyps. Am Surg. 1988;54:61-3.

20. Van Gossum A, Cozzoli A, Adler M, Taton G, Cremer M. Colonoscopic snare polypectomy: analysis of 1485 resections comparing two types of current. Gastrointest Endosc. 1992;38:472-5.

21. Fujishiro M, Yahagi N, Kakushima N, Kodashima S, Muraki Y, Ono S, et al. Successful nonsurgical management of perforation complicating endoscopic submucosal dissection of gastrointestinal epithelial neoplasms. Endoscopy. 2006;38:1001-6.

22. Jeong G, Lee JH, Yu MK, Moon W, Rhee PL, Paik SW, et al. Non-surgical management of microperforation induced by EMR of the stomach. Dig Liver Dis. 2006;38:605-8.

23. Minami S, Gotoda T, Ono H, Oda I, Hamanaka H. Complete endoscopic closure of gastric perforation induced by endoscopic resection of early gastric cancer using endoclips can prevent surgery (with video). Gastrointest Endosc. 2006;63:596-601.

24. Abe $\mathrm{Y}$, Inamori M, Iida H, Endo H, Akiyama T, Yoneda K, et al. Clinical characteristics of patients with gastric perforation 
following endoscopic submucosal resection for gastric cancer. Hepatogastroenterology. 2009;56:921-4.

25. Takizawa K, Oda I, Gotoda T, Yokoi C, Matsuda T, Saito Y, et al. Routine coagulation of visible vessels may prevent delayed bleeding after endoscopic submucosal dissection-an analysis of risk factors. Endoscopy. 2008;40:179-83.
26. Katsinelos P, Kountouras J, Paroutoglou G, Chatzimavroudis G, Zavos C, Pilpilidis I, et al. A comparative study of $50 \%$ dextrose and normal saline solution on their ability to create submucosal fluid cushions for endoscopic resection of sessile rectosigmoid polyps. Gastrointest Endosc. 2008;68:692-8. 